$$
E_{t}=E_{0}-A \log t,
$$

where $E_{0}$ is the efficiency at weaning and $A$ is a constant. This function decreases rapidly, and on the thirtieth day of post-weaning life the gross efficiency is only about one-third of the value at weaning. In subsequent publications ${ }^{2}$ it was pointed out, however, that the thermochemical significance of weight increments varies with age, as do the proportions of water retained and of protein and fats synthesized, so that consideration of gross efficiency does not adequately represent the energetics of growth, any more than the weight curve does.

It has now been possible to follow accurately what we shall call the 'thermochemical efficiency' of growth and define as the ratio of the increment in total heat content of the body corresponding to a given period to the energy content of the foodstuffs ingested during this period. The albino rat was again used as the experimental animal. Records of food intakes were kept and body analyses conducted on well over a hundred animals, the animals being killed at intervals during the first ninety days of post-weaning life. The full analytical data and results of this experiment, as well as various conclusions not pertinent to this particular subject, will be published later elsewhere. The facts relevant to the subject under consideration are as follows: While the gross (ponderal) efficiency of growth steadily declines from the time of weaning, the thermochemical efficiency, of the order of 24 per cent at weaning, remains remarkably constant throughout the period of active growth and does not begin to decline until the fiftieth day. The inflexion point of the weight curve is situated between the eighteenth and the twentieth day of postweaning life. This point is also found to correspond to some important changes in the trend of evolution of body composition; while the percentage of protein on a weight basis remains constant (and of the order of 17 per cent) throughout the first three months of independent, post-weaning growth, the percentage of water starts decreasing at the time of the inflexion, and the ever-increasing proportion of fat reaches then the point where the heat content of body fat becomes larger than that of body protein. The period of inflexion also corresponds to a decrease in the rate of increase of the daily food intake, a linear function of time until then. Yet this period corresponds to no remarkable point on the curves representing either total body-heat content or thermochemical efficiency as functions of time. It is a period of marked shift in metabolism, characterized by a decrease in the proportion of energy stored in protein and a decrease in water retained and hence in rate of gain of weight, but not by a decrease in thermochemical efficiency. Similarly, the thirtieth day after weaning, the time of development at which the adult, 'plateaued' food intake is reached, does not correspond to any singular point on the heat content or thermo. chemical efficiency curves. The whole period of growth is, of course, characterized by a rapidly increasing average body-heat content, from 1.4 calories per gram at weaning to 3 calories per gram ninety days later.

Reviewing these various facts, it appears legitimate to deduce the two following laws, valid for the growth of the albino rat fed an adequate diet and maintained in a constant environment.

(1) The protein content expressed on a proportional weight basis is constant throughout growth.
(2) The water and fat contents, body-weight, total heat content and food intake vary so that the thermochemical efficiency of growth is constant from weaning to puberty.

This work was supported in part by grants from the American Meat Institute, Chicago, Ill.; Swift and Co., Chicago, Ill. ; Research Corporation, New York, N.Y.; and the United States Public Health Service, Washington, D.C.

$$
\begin{aligned}
& \text { Jean Mayer } \\
& \text { J. J. VItale } \\
& \text { T. K. TaIra }
\end{aligned}
$$

Department of Nutrition,

Harvard University School of Public Health, Boston 15, Mass. Oct. 30

'Mayer, Jean, Yale J. Biol. Med., 21, 416 (1949).

${ }^{2}$ Mayer, Jean, Nature, 164, 65 (1949); Growth, 13, 97 (1949).

\section{Susceptibility of the Indian Garden Squirrel (Sciurus palmarum) to Plasmodium berghei and its Asexual Periodicity}

THw discovery of $P$. berghei by Vincke and Lips ${ }^{1}$ in Thamnonys, a tree rat in the Belgian Congo, was followed by the study of the parasite in rats and mice. Rodhain ${ }^{2}$ successfully infected the cotton rat with the parasite. Adler, Yoeli and Zuckerman ${ }^{3}$ found that the golden hamster and the field vole were susceptible to $P$. berghei infections.

In the course of studies in these laboratories, the garden squirrel ( $S$. palmarum) has been found to be susceptible to blood-induced infections of $P$. berghei. In these rodents, unlike mice and some rats, the infection was mild and became chronic. Periods of latency were followed by mild parasitic relapses. Typical band forms of parasites as seen in P. malarice infections in human beings were common.

Four-hourly smears from four mice, two rats and two squirrels infected with $P$. berghei were studied, and the different stages of parasites were enumerated in accordance with the method described by Mulligan". In all these animals, $P$. berghe $i$ was found to have a periodicity of twenty-four hours. The maturation of schizonts occurred between $6.00 \mathrm{a} . \mathrm{m}$. and $10.00 \mathrm{a.m}$. every day.

\section{S. P. RamakrishnaN Satya Prakash}

Malaria Institute of India, Delhi.

Nov. 11.

'Vincke, Y. H., and Lips, M., Ann. Soc. Belge de Med. Trop., 88, 97 (1948).

${ }^{2}$ Rodhain, J., Ann. Soc. Belge de Med. Trop., 29, 483 (1949).

${ }^{3}$ Adler, S., Yoeli, M., and Zuckerman, A., Nature, 166, 571 (1950).

"Mulligan, H. W., Arch. Protist., 84, 285 (1935).

\section{Cyst-forming Eelworms on Cruciferous Plants}

IN the course of investigations on certain pests of Brassicas, I observed that in some fields in Thanet the crops were infested with parasitic eelworms of the genus Heterodera. To understand their importance on the crops it was necessary to determine the species ; but here I met with difficulties. According to Franklin ${ }^{1}$ and Jones ${ }^{2}$, two species attack crucifers : H. schachtii Schmidt and H. cruciferce Franklin. 